\title{
Cognitive Styles as Predictors of Managerial Effectiveness: A Study of Private Sector Managers from Manufacturing Industries
}

\author{
Dr. Ishita Chatterjee ${ }^{1}$, Sravasti Dey ${ }^{2}$
}

Keywords: Predictors, Private Sector, Manager, Manufacturing Industries

One of the advantages, the Indian Industries had, was the quality combined with low cost. In recent years, this advantage is waning away because of the invasion of World market by cheaper products from China (Seetharama, 2012). This challenge can be overcome by producing quality products at reduced costs, which in turn requires faster and efficient design, manufacturing methods and effective managers for monitoring.

Cognitive style is described as the way individuals imagine, perceive, distinguish, recognize, think and remember information (Rishipal, 2012). It is a persisting habitual pattern of perceptual and intellectual activity. With the help of cognitive styles an individual acquires knowledge (cognition) and processes information (conceptualization).

Different types of studies and research have been conducted recently to evaluate the impacts and effects of cognitive styles and competencies on predicting organizational behavior, performance and results (Jamshidi, Khosravi, Harirchian, Samadi, 2014). Cognitive style's assessment is useful in prediction of learning in job training (Jamshidi, Zeinshavzi, Ghasemi, 2012). Cognitive theory has revealed means of which individuals can be more resilient in ways of processing information (Ahangar, 2010). In a study in Malaysia it was found a correlation between resilience and cognitive styles - among two different generations, it was considered vital because understanding cognitive styles may lead individuals to develop accurate beliefs about the World and appropriate strategies may result in valuable resilience resources (Zamani, Nasir, Sulaiman, Khairudin, Halim, 2014). Cognitive styles are linked to mental behaviours, habitually applied by an individual for problem solving, and generally the way that information is obtained, sorted and utilized. Cognitive style being the recurring perceptual and intellectual pattern of personality which can influence attitudes, values and social interaction (Rishipal, 2012). Cognitive style has been found as an important human - related factor for project managers, contributing to their soft skills (Esa, Alias, and Samad, 2014). Cognitive styles affect not only higher order cognitive processing but also perception and attention (Kozhevnikov, Evans, and Kosslyn, 2014).

\footnotetext{
${ }^{1}$ Assistant Professor, Department of Applied Psychology, University of Calcutta.

${ }^{2}$ Research Student, Department of Applied Psychology, University of Calcutta.

(C) 2015 I I Chatterjee, S Dey; licensee IJIP. This is an Open Access Research distributed under the terms of the Creative Commons Attribution License (http://creativecommons.org/licenses/by/2.0), which permits unrestricted use, distribution, and reproduction in any Medium, provided the original work is properly cited.
} 


\section{MANAGERIAL EFFECTIVENESS:}

Increasing competition around the globe requires a cadre of effective managers for operations in their organizations. The traditional model of managerial effectiveness emphasizes the ability to set and achieve goals where it is implicitly assumed that managerial effectiveness leads to organizational effectiveness. In the context of an employee's specific role within an organization, managerial effectiveness is a product of the individual's effective or ineffective work - related behaviors (Page, Wilson, Meyer and Inkson, 2003).

Effective managers, similar to effective organizations, need to simultaneously manage a multitude of relationships with individuals and groups affected by their actions and behaviours. Managerial effectiveness has been measured in terms of three components - 1) Productivity: which included production output and services, optimum utilization of resources, problem anticipation and management of unforeseen consequences, adaptation of new method of doing work. 2) Adaptability: it is acceptance of changes made in the system of organization, adjustment to new work environment. 3) Flexibility: it includes quality of service and products, cope with emergencies more readily and successfully (Bamel, Rangnekar, and Rastogi, 2011).

Effectiveness involves doing the right things in the right way. Effectiveness is particularly important in the case of managers as they are responsible for the performance of others (Ali and patnaik, 2014).

Zhang (2010) investigated the characteristics of organizational climate and its effect on organizational variables. He pointed out that organizational climate had significant main effects on human resources management effectiveness.

Catherine and Cherly (2007) revealed that organizational culture was strongly perceived as being related to both leadership effectiveness (explaining $40 \%$ of the variance) and personal effectiveness (24\% of the variance).

Managerial effectiveness is very important for the survival and growth of the organization. A review of literature shows that managerial effectiveness has been studied with three perspectives - Traditional/ Conventional Perspective, Organizational Level Competency Based Perspective, and An Individual Level Competency Based Perspective.

A manager should have a combination of technical, interpersonal and conceptual skills that can make him an effective manager (Rishipal, 2012).

Effectiveness of executives is very important for the success of an organization in the contemporary business arena (Bao, 2005). Executives employ their competencies and enhance the economic value of raw resources to play a crucial role in the development and execution of 
organizational operations and effectiveness of the implemented strategies / policies (Analoui, 2007).

Managerial Effectiveness depends on a number of factors like individual's perception, personality, superior subordinate relation, working style, trust facilitation, way of thinking \& processing information and surrounding organizational climate (Sternberg, R.J., \& Zhang, L.F., 2001). Most of these factors of managerial effectiveness are element of cognitive style also, so there might exist a relationship between Managerial Effectiveness and cognitive style which should be investigated and understood. There has not been sufficient research to investigate the relative importance of different facets of cognitive style in predicting managerial effectiveness. So far, little has been done about whether there is a genuine relationship between cognitive style and managerial effectiveness.

\section{METHODOLOGY}

\section{Objectives:}

1. To study the difference in overall management style among the Junior level Managers and Middle level Managers.

2. To study the significance difference between Junior level Managers and Middle level Managers with respect to cognitive styles (Systematic Cognitive Style and Intuitive Cognitive Style).

3. To study the relationship between the Cognitive Styles and three dimensions of Managerial Effectiveness.

4. To study if Cognitive Styles (Systematic Cognitive Style and Intuitive Cognitive Style) would positively predict the three dimensions of Managerial Effectiveness (Productivity, Adoptability, and Flexibility).

\section{Description of the Tools:}

1. The Cognitive Style Inventory: This inventory is constructed and published by Pfeffer Library, 1998 which consists of 40 statements half of each pertains to Systematic Style and half to Intuitive Style. Respondents evaluate each statement according to the degree to which they agree with it. The Cronbach's alpha was found to be 0.69 and 0.73 respectively for the present sample. The inventory has adequate face validity.

2. Index Managerial Effectiveness Scale: This scale was adopted from Mott, 1971 by Bamel, Rangnekar and Rastogi in 2011. Eight items were grouped into three factors Productivity (production output, optimum utilization of resources and adaptation of new method of production), Adoptability (quality, problem anticipation and acceptance of changes), and Flexibility (adjustment to the new situation and copes with emergencies readily and successfully). The Cronbach's alpha was found to be $0.78,0.69$ and 0.78 for Productivity, Adoptability and Flexibility. The scale has adequate face validity. 


\section{Sample:}

A sample of 72 Junior Level Managers and 78 Middle Level Managers from 8 private Manufacturing Industries was taken for the study. The private manufacturing companies were located in Bihar, Jharkhand, and West Bengal. The Educational Qualification was Graduation in Engineering to Masters in Engineering with Management Degree or Diplomas. Working Experience in Manufacturing Industries for at least 5 years. Age ranged from 40 to 50 years.

\section{RESULT}

Table 1.1: Mean and SD of the scores in Cognitive Style and Managerial Effectiveness.

\begin{tabular}{|l|l|l|l|l|l|l|}
\hline \multirow{2}{*}{} & \multicolumn{2}{|l|}{$\begin{array}{l}\text { Systematic } \\
\text { Style }\end{array}$} & \multicolumn{2}{l|}{ Intuitive Style } & \multicolumn{2}{l|}{$\begin{array}{l}\text { Managerial } \\
\text { Effectiveness }\end{array}$} \\
\cline { 2 - 7 } & Mean & SD & Mean & SD & Mean & SD \\
\hline $\begin{array}{l}\text { Junior } \\
\text { Managers }\end{array}$ & 72.50 & 5.57 & 71 & 6.35 & 29.36 & 3.38 \\
\hline $\begin{array}{l}\text { Middle } \\
\text { Managers }\end{array}$ & 74.50 & 5.90 & 73.20 & 6.44 & 30.30 & 4.45 \\
\hline
\end{tabular}

This table reveals a moderate level of Managerial Effectiveness of both Junior and Middle Managers.

Table 1.2: $t$ value between Junior and Middle Managers

\begin{tabular}{|l|l|l|}
\hline Systematic Style & Intuitive Style & Managerial Effectiveness \\
\hline 1.45 & 1.48 & 0.95 \\
\hline
\end{tabular}

This table reveals low significance difference among Junior and Middle Managers with respect to Cognitive Styles (Systematic Style and Intuitive Style) and overall Managerial Effectiveness. Since $\mathrm{t}$ - value was insignificant; rest of the statistical analysis was done by combining the data.

Table 2: Bivariate Correlation between Cognitive Styles and Managerial Effectiveness

\begin{tabular}{|l|l|l|}
\hline & Systematic Cognitive Style & Intuitive Cognitive Style \\
\hline Productivity & $0.48^{* *}$ & $0.68^{* *}$ \\
\hline Adoptability & $0.53^{* *}$ & $0.26^{*}$ \\
\hline Flexibility & $0.51^{* *}$ & $0.28^{*}$ \\
\hline
\end{tabular}

This table reveals a significant correlation between Cognitive Styles and three dimensions of Managerial Effectiveness, i.e., Productivity, Adoptability, Flexibility. Systematic Cognitive Style was more significantly related to Adoptability followed by Flexibility and Productivity respectively, while Intuitive Cognitive Style was highly related to Productivity and showed low relationship with Adoptability and Flexibility. 
Table 3.1: Linear Regression Analysis for Productivity

\begin{tabular}{|c|c|c|c|c|c|c|}
\hline Variables & $\beta$ & $\mathrm{t}$ & \begin{tabular}{|l} 
Significance \\
Value \\
\end{tabular} & $\mathrm{R}$ & $\begin{array}{l}\text { Adjusted } \\
\mathrm{R}^{2} \\
\end{array}$ & $\begin{array}{l}\text { Value with } \\
\text { Significance }\end{array}$ \\
\hline Constant & & 3.488 & 0.001 & \multirow{3}{*}{0.344} & \multirow{3}{*}{0.062} & \multirow{3}{*}{$2.076^{*}$} \\
\hline $\begin{array}{l}\text { Systematic } \\
\text { Cognitive Style }\end{array}$ & 0.270 & 2.35 & 0.02 & & & \\
\hline $\begin{array}{l}\text { Intuitive Cognitive } \\
\text { Style }\end{array}$ & 0.356 & 2.58 & 0.017 & & & \\
\hline
\end{tabular}

This table reveals that both Systematic Cognitive Style and Intuitive Cognitive Style were positive predictors of Productivity.

Table 3.2: Linear Regression Analysis for Adoptability.

\begin{tabular}{|l|l|l|l|l|l|l|}
\hline Variables & $\beta$ & $\mathrm{t}$ & $\begin{array}{l}\text { Significance } \\
\text { Value }\end{array}$ & $\mathrm{R}$ & $\begin{array}{l}\text { Adjusted } \\
\mathrm{R}^{2}\end{array}$ & $\begin{array}{l}\text { Value with } \\
\text { Significance }\end{array}$ \\
\hline Constant & & 2.98 & 0.01 & 0.323 & 0.057 & $2.86^{* *}$ \\
\cline { 1 - 1 } $\begin{array}{l}\text { Systematic } \\
\text { Cognitive Style }\end{array}$ & 0.36 & 2.58 & 0.01 & & & \\
\cline { 1 - 4 } $\begin{array}{l}\text { Intuitive } \\
\text { Cognitive Style }\end{array}$ & 0.19 & 1.02 & Not significant & & & \\
\hline
\end{tabular}

This table reveals that Systematic Cognitive style was a positive predictor of Adoptability, while intuitive style was not a significant predictor.

Table 3.3: Linear Regression Analysis for Flexibility.

\begin{tabular}{|l|l|l|l|l|l|l|}
\hline Variables & $\beta$ & $\mathrm{t}$ & $\begin{array}{l}\text { Significance } \\
\text { Value }\end{array}$ & $\mathrm{R}$ & $\begin{array}{l}\text { Adjusted } \\
\mathrm{R}^{2}\end{array}$ & $\begin{array}{l}\text { Value with } \\
\text { Significance }\end{array}$ \\
\hline Constant & & 2.95 & 0.01 & \multirow{2}{*}{0.223} & 0.443 & $2.043^{*}$ \\
\hline $\begin{array}{l}\text { Systematic } \\
\text { Cognitive Style }\end{array}$ & 0.37 & 2.78 & 0.01 & & & \\
\cline { 1 - 5 } $\begin{array}{l}\text { Intuitive } \\
\text { Cognitive Style }\end{array}$ & 0.143 & 0.983 & Not significant & & & \\
\hline
\end{tabular}

This table reveals that Systematic Cognitive style was a positive predictor of Flexibility, while intuitive style was not a significant predictor.

\section{DISCUSSION:}

Leadership is widely considered to be an important aspect of organizing and there are several reasons to suggest that managerial styles are of particular relevance in this context. However, there is a dearth of both theoretical and empirical work on leadership styles and their subsequent effects on middle managers' organizational commitment, their job satisfaction, their communication and their managerial effectiveness. The factors of Managerial Effectiveness are also element of Cognitive Style. So there might exist a relationship between Managerial Effectiveness and Cognitive Style, which was investigated for understanding. 
Here it was found that both Systematic Cognitive Style and Intuitive Cognitive Style were significantly and positively correlated with Managerial Effectiveness.

Intuition can be defined as the skill to capture a thought or to formulate a decision about motivation properties without being capable to submit plainly to the information or inference as core to the result (Chau, Schacter \& Sperling, 2008). Basing a decision upon intuition is perceived to be mostly in contrast to rationality and devoid of veridical knowledge. Therefore Intuitive Cognitive Style has not been able to predict Flexibility and Adoptability dimensions of Managerial Effectiveness. Intuitive Cognitive Style is a personal style of information processing and decision - making attributed to novelty and excitement in contrast to stability and safety. Thus the style fails to predict Flexibility and Adoptability. Intuitive Cognitive Style Managers can decide rapidly with very limited information. Therefore they can decide strategies and take decisions related to production. But here a question lies as to the reliability of their intuitions, not much research has been done in this area. Individuals should be encouraged to use both analytic and intuitive style in decision making for optimum results (Syagga, 2012).

In Systematic Cognitive Style people apply rule - based thinking, allowing them to go through a systematic process. Thus they are more objective in their approach in contrast to intuitive style which is more subjective; they can easily adapt and can be more flexible. Individual differences in Cognitive Style are also a very common phenomenon (Poore, Forlines, Miller, Regan and Irvine, 2012).

The findings go somewhat in line with an early experiment of Sagiv, Amit, Ein - Gar, and Arielis (2013), who found Intuitive Style persons did not show any improvement in rule - based performance. Systematic Style was positively correlated with conscientiousness and security values and negatively correlated with stimulation values. The Intuitive style had opposite pattern and was also positively correlated with Extraversion. Cognitive Style is consistent with other personal attributes (Traits and Values), with implications for decision making and task performance. Kumar and Nagarjun (2014) in an Indian Sample also found that cognitive style varies with the management type and value system has a bearing on the Cognitive Style.

\section{IMPLICATION:}

The study will help the managers to identify their cognitive styles and relate to the different aspects of Managerial Effectiveness. So as to design and prescribe different developmental strategies that can enhance Managerial Effectiveness and decision making for proper selection and recruitment. To increase flexibility in various problem solving situations and improve the interaction between individuals and groups. Effective Management is important because: 
- Good managers are the key to a more competitive economy and higher performing enterprises

- Job creation depends on better management skills

- Must improve to meet today's world best practice standards and the challenges of the Asia-Pacific century

\section{LIMITATION AND SUGGESTION:}

Because of limited resources, sample size was inadequate. If a larger sample could be taken and more areas and industries would be covered, the sampling error would be much reduced and scope for generalization could be increased.

More work can be taken for exploring the reliability of Intuitive Style and taking people with other Cognitive Styles like Split Styles and Undifferentiated Styles and study their relation to Managerial Effectiveness. This study could be extended to other sectors other than manufacturing.

\section{REFERENCES:}

Ahangar, R. G. (2010). A Study of Resilience in Relation to Personality, Cognitive Styles and Decision Making Style of Management Students.

Ali, A., \& Patnaik, B. (2014). Influence of Organizational Climate and Organizational Culture on Managerial Effectiveness: An Inquisitive Study. The Carrington Rand Journal of Social Sciences, Volume : 1, No. 2001 - 2020.

Analoui, F. (2007). Strategic Human Resource Management, London: Thompson Learning.

Bamel, U. K., Rangnekar, S., \& Rastogi, K. (2011). Managerial Effectiveness in Indian Organizations: Reexaming an Instrument in an Indian Context. Research and Practice in Human Resource Management, 19 (1), 69 - 78.

Bao, C. (2009). Comparison of Public and Private Sector Managerial Effectiveness in China: A Three Parameter Approach. Journal of Management Development, 28 (6), 533 - 541.

Catherine, T. K., \& Cheryl, A.B. (2007). Perceptions of Organizational Culture, Leadership Effectiveness and Personal Effectiveness Across Six Countries. Journal of International Management: 13 (2), 178 - 195.

Chua, E.F., Schachter, D. L., \& Sperling, R.A. (2008). Neural Correlates of Meta Memory: A Comparison of Feeling - of - Knowing and Retrospective Confidence Judgements. Journal of Cognitive Neuroscience, 21 (9), 1751 - 1765.

Esa, M., Alias, A., Samad, A. Z. (2014). Project Managers' Cognitive Style in Decision Making: A Perspective from Construction Industry. International Journal of Psychological Studies; Vol , 6, No - 2, $65-73$.

Jamshidi, M.H. M., Zeinahvazi, Khosravi, G.V.,Harirchian, E., Samadi, M. (2014). The Study of Relationship Between Cognitive Styles and Human Resource Competencies in Iranian Construction Industries. Volume - 40, Issue - 1, 796 - 804. 
Jamshidi, M.H. M., Zeinahvazi, M., Adel, H., and Ghasemi, P. (2012). Essential Competencies for the Human Resource Managers and Professionals in Construction Industries. Journal of Basic and Applied Scientific Research, Vol - 2, Issue 6, 5694 - 5702.

Kozhevnikov, M.,Evans, C., Kosslyn, M.S. (2014). Cognitive Style as Environmentally Sensitive Individual Differences in Cognition: A Modern Synthesis and Applications in Education, Business and Management.

Kumar, S.D., \& Nagaraju, k. (2014). Cognitive Styles of High School Mathematics Teachers. Scholarly Research Journal for Humanity Science \& English Language, Volume - 7, 425 $-431$.

Page, C., Wilson, M., Meyer D., \& Inkson, K. (2003). “ It's the Situation I'm in”: The Importance of Managerial Context to Effectiveness". Journal of Management Development, Volume - 22, Issue - 10, 841 - 862.

Poore, C.J., Forlines, L. C., Miller, M. S., Regan, J. R., Irvine, M. J. (2014). Personality, Cognitive Style, Motivation and Aptitude Predict Systematic Trends in Analytic Forecasting Behavior. Journal of Cognitive Engineering and Decision Making, Volume 8, No - 4, $374-393$.

Rishipal (2012). Cognitive Style a Predictor of Managerial Effectiveness: Study of Public and Private Sector Bank Managers in India. Global Journal of Management and Business Research. Vol - 12, Isuue - 2, 20 - 26.

Sagiv, L., Amit, A., Ein - Gar, D., \& Arieli, S. (2013). Not All Great Minds Think Alike: Systematic And Intuitive Cognitive Styles. Journal of Personality Wiley Periodical, 12071, $1-16$.

Seetharama, K.S. (2012). Solution to Challenges Faced by Indian Industries: Designing with Multi - Enterprise Partnership. International Journal of Engineering Science and Innovative Technology. Vol - 1, Issue - 2, 150 - 153,

Sternberg, Robert J., and Zhang, Li-Fang (Eds.). (2001). Perspectives on Thinking, Learning, and Cognitive Styles, International Review of Education, Volume 48, Issue 6, pp 525-532

Syagga, L. A. (2012). Intuitive Cognitive Style and Biases in Decision Making. Institute of Graduate Studies and Research, Unpublished Master Thesis, Eastern Mediterranean University.

Zamini, A. Z., Nasir, R., Sulaiman, S. W., Khairudin, R., Fatimahwati, H. (2014). Resilience and Cognitive Styles Among Pre - Post Independence Generations in Malaysia. Procedia Social and Behavioural Sciences 140, $145-149$.

Zhang, J. (2010). Organizational Climate and Its Effect on Organizational Variables: An Empirical Study. International Journal of Psychological Studies, 2(2), 189 - 201. 